\title{
Um estudo sobre colaboração logística entre indústria de bens de consumo e redes de varejo supermercadista
}

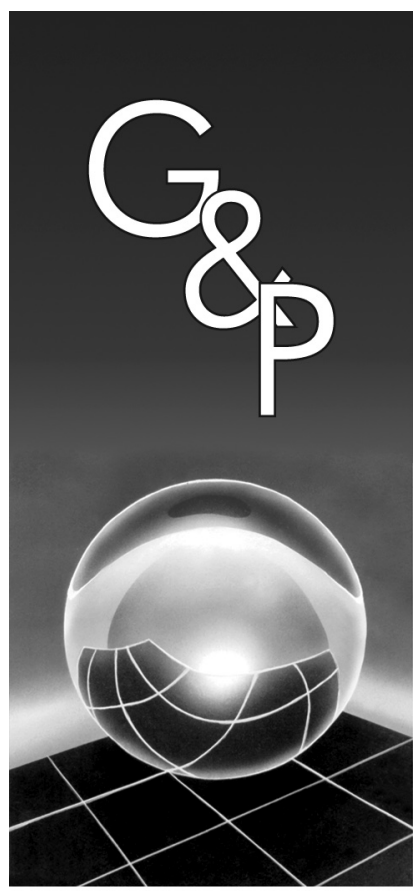

\author{
José Geraldo Vidal Vieira \\ Hugo Tsugunobu Yoshida Yoshizaki \\ Linda Lee Ho
}

\section{Resumo}

Este artigo visa conhecer o estado de colaboração em logística entre indústrias fornecedoras e redes de supermercados do Brasil, por meio do estudo da relação entre os elementos de colaboração e os elementos de desempenho logístico e de custos de transação identificados na relação de parceria. A metodologia é composta por uma análise qualitativa (por meio de observação participativa) e quantitativa, composta por uma amostra de 125 representantes dos fornecedores de 87 fabricantes de bens de consumo. Foram avaliadas as quatro maiores redes supermercadistas atuantes no país. Por meio de testes estatísticos e modelos de regressão, os resultados mostraram que alguns elementos de colaboração influenciam positivamente o desempenho logístico dos fornecedores, principalmente tratando-se de desempenho logístico diferenciado (entregas urgentes e em períodos de demanda alta). A integração interpessoal é a que mais contribui para a maior intensidade de colaboração, seguida da integração estratégica e integração tática. A maior intensidade de integração estratégica e de ações conjuntas (relacionadas aos elementos de integração tática) contribui para a diminuição de incertezas entre os participantes e essas ações conjuntas contribuem para o aumento do investimento em ativos específicos.

Palavras-chave: Elementos de colaboração. Desempenho logístico. Custos de transação. Varejo.

\section{Introdução}

Na década de 90, o tempo médio para uma empresa processar e entregar um pedido variava de 25 a 30 dias e os erros na entrega eram frequentes, o que gerava uma maior necessidade de estoque em todos os elos da cadeia de suprimentos: fabricantes, atacadistas, distribuidores e varejistas (BOWERSOX; CLOSS; COOPER, 2006). Todavia, com o advento da globalização, este cenário vem se transformando devido às novas demandas provenientes dos altos níveis de competição nacional e internacional. Neste contexto, a aceleração no atendimento aos pedidos tem destaque no tocante à melhoria do desempenho logístico na gestão da cadeia de suprimentos (PAVAN; PIRES, 2004) e à construção de alianças estratégicas entre as empresas. Sabe-se que o sucesso de cada firma depende, em parte, de outras, que, juntas, procuram satisfazer as necessidades dos consumidores finais (ANDERSON; NARUS, 1990; FROHLICH; WESTBROOK, 2001; SIMATUPANG; SRIDHARAN, 2002; CHOI et al., 2002).

As grandes redes de supermercados e seus fornecedores têm investido em novos modelos de parcerias ou acordos colaborativos para melhorar seu desempenho e evitar o retrabalho nas operações logísticas, reduzindo custos desnecessários.

Este artigo tem por objetivo quantificar o impacto dos elementos de colaboração no desempenho logístico e nos custos de transação e, adicionalmente, avaliar os elementos mais importantes sob a ótica dos representantes da indústria. Para tanto, foram levantados os elementos avaliados por meio de um estudo de caso realizado em uma grande rede de varejo durante 11 meses. Posteriormente, estes foram analisados por técnicas estatísticas (teste $t$, teste $t$ para dados emparelhados e análise de regressão).

\section{Referencial teórico}

\subsection{Elementos de colaboração}

Os elementos de colaboração apresentados a seguir são baseados no trabalho publicado por Vieira, Yoshizaki e 
Ho (2009). Os autores agruparam os elementos de colaboração em três conjuntos indissociáveis: integração estratégica, integração tática e integração interpessoal.

- Integração estratégica: composto pelo compartilhamento de informações de estoque; conhecimento das estratégias e dificuldades do parceiro; histórico de relacionamento e envolvimento da alta gerência. Os elementos denominados pelos autores de integração estratégica fazem parte do escopo de qualquer relacionamento entre parceiros. Pressupõe-se maior intensidade de colaboração se os participantes estiveram envolvidos em ações conjuntas, realizarem visitas técnicas ao parceiro e desenvolverem relacionamentos de longo prazo (VIEIRA; YOSHIZAKI; LUSTOSA, 2010).

- Integração tática: os elementos de integração tática se referem aos gerentes e supervisores que trabalham com projetos específicos ou atividades conjuntas entre as áreas funcionais envolvidas de duas empresas. Esses gerentes são responsáveis por sugerir mudanças na organização (como composição de equipes, liderança, definição das tarefas e incorporação de rotinas em sistema para troca automática de dados), com o objetivo de conectar eficientemente as duas organizações e permitir melhor troca de informação entre as equipes, ou seja, verificar qual a melhor maneira de realizar a transação (KANTER, 1994).

Os três subgrupos que compõem os elementos táticos são desmembrados em:

1) ações conjuntas: referem-se às interações entre as áreas funcionais, como ter equipes dedicadas aos processos logísticos com os parceiros, participação conjunta em seminários da área de logística, compartilhamento de metas e planos logísticos, projetos logísticos conjuntos, sistemas de informação utilizados para a troca automática de dados e comunicação diária (aberta e transparente);

2) compartilhamento de custos e ganhos logísticos: tem como atributos o compartilhamento de custos com entrega, o compartilhamento de custos com devolução de produto, o compartilhamento de ganhos logísticos e o compartilhamento de custos para identificação de causas de ruptura (ou falta de produto no ponto de venda); e

3) compartilhamento de informações logísticas e comerciais: composto pelos atributos compartilhamento de eventos promocionais; compartilhamento de informação de dados de ponto de venda; compartilhamento de dados de previsão de vendas; planejamento conjunto de sortimento de produto; planejamento conjunto de eventos promocionais, e planejamento conjunto de pedido (SIMATUPANG; SRIDHARAN, 2005). A eficiência no compartilhamento dessas informações reduz as assimetrias de informação e pode levar a redução dos custos e a aumentar a frequência na transação (POPP, 2000).

Segundo Kim (1999), o envolvimento dos parceiros nessas ações conjuntas (logísticas e comerciais) e no compartilhamento de ganhos e custos pode resultar em fontes de vantagem competitivas, no sentido de melhor cumprimento de suas metas e melhor atendimento das necessidades dos consumidores finais.

- Integração interpessoal: composto pelos elementos confiança, interdependência, flexibilidade e reciprocidade. Esses elementos se referem ao comportamento dos parceiros e ao ambiente interpessoal e organizacional das empresas. Para Kanter (1994), a integração interpessoal refere-se à construção de uma base de relacionamento sustentável entre os parceiros com o objetivo de criar valor futuro.

A Figura 1 ilustra os principais elementos que formam o conceito de colaboração. Os elementos de integração estratégica são responsáveis pela definição das metas e objetivos da parceria e os elementos interpessoais pelo comportamento dos parceiros, influenciados principalmente pela confiança interorganizacional e interpessoal (VIEIRA; YOSHIZAKI; HO, 2009). Neste sentido, há influência direta entre esses dois tipos de integração, pois não há troca de informações estratégicas sem ter confiança no parceiro. Ou seja: parece que os parceiros privilegiam o relacionamento pessoal com os seus parceiros comerciais antes de discutir a transação em si. Também dificilmente haverá reciprocidade e interdependência (com troca de informações estratégicas) sem se conhecerem as dificuldades e potencialidades logísticas do parceiro.

Por um lado, os elementos de integração estratégica e os elementos interpessoais influenciam diretamente os

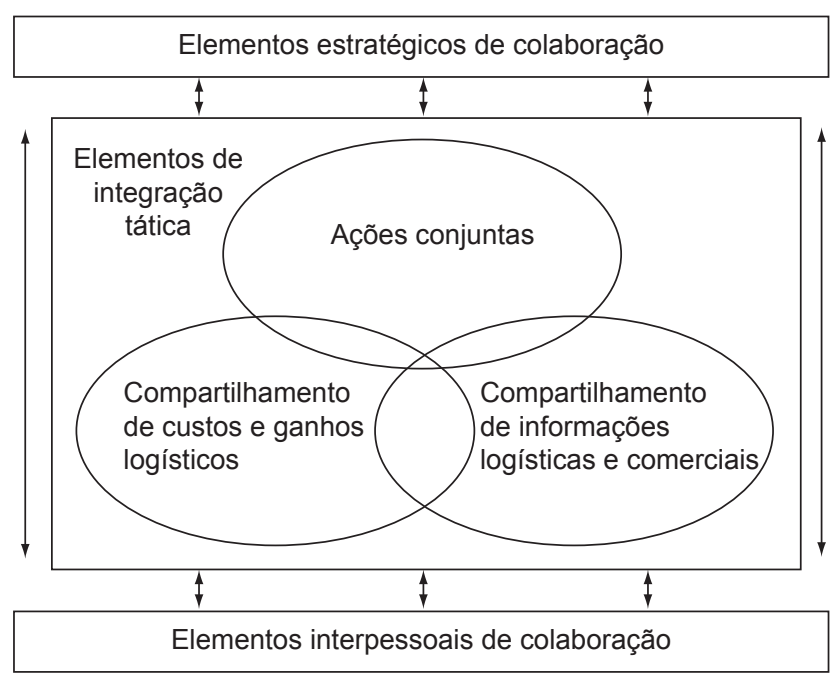

Figura 1. Elementos de colaboração. Fonte: Vieira, Yoshizaki e Ho, 2009. 
elementos de integração tática, pois os dois primeiros são considerados a base do processo de colaboração (Barratt, 2004). Assim, em relação à integração estratégica, à medida que aumenta o envolvimento da alta gerência na realização de acordos logísticos colaborativos, mais ações e projetos conjuntos são desencadeados na busca de aumentar a eficiência logística no tocante a cumprimento dos prazos, redução dos estoques e diminuição da ruptura de gôndola; consequentemente, melhora-se a integração tática. Segundo Vieira, Yoshizaki e Lustosa (2010), as visitas técnicas são atributos facilitadores nesta integração. De forma semelhante, em relação à integração interpessoal, à medida que aumentam a flexibilidade e a interdependência na relação, maior se torna o compartilhamento de informações logísticas e comerciais.

Por outro lado, os elementos de integração tática se desenvolvem pela constante interação entre os parceiros nas tomadas de decisões conjuntas e no compartilhamento de informações e incentivos logísticos, o que permite aumentar a confiança, a flexibilidade na resolução de contingências e a dependência entre as partes. Assim, os elementos de integração tática também influenciam os elementos de integração interpessoal. O mesmo acontece quando há maior compartilhamento de custos e ganhos logísticos entre os parceiros, fazendo com que haja maior interação entre diretores e gerentes das empresas na busca de reduzir custos logísticos operacionais (por exemplo, custo de entrega, custo de armazenagem e movimentação) e, consequentemente, oferecer melhores serviços e preços ao consumidor final. Um exemplo: são acordos de colaboração que incluem fretes de retornos, retornos de paletes, cross-docking e estoque gerenciado pelo fornecedor (ou Vendor Managed Inventory - VMI).

A partir da Figura 1, podem-se levantar proposições acerca de quais dessas três integrações são responsáveis pelo maior grau de colaboração entre os parceiros. Para um estágio mais evoluído de colaboração, os parceiros têm como base a integração estratégica e a integração interpessoal, pois estas integrações reúnem elementos que se solidificam ao longo do tempo. O grau dessas integrações poderá indicar qual estágio de colaboração entre os parceiros (transacional, coordenação, parceria ou integração) prevalece (WILDING; HUMPHRIES, 2006). Assim, para uma cadeia de varejo, se houver um bom histórico de relacionamento, uma boa troca de informações estratégicas, interdependência na relação e investimentos na parceria com visão de longo prazo, ou seja, um elevado grau de integração estratégica e interpessoal, a colaboração tende à parceria ou à integração. No mesmo sentido, se a integração tática (as ações conjuntas e troca de dados operacionais entre os parceiros) tiver intensidade maior do que as demais integrações, isto pode indicar o estágio da coordenação de algumas atividades logísticas.

\subsection{Elementos de desempenho logístico}

Os elementos de desempenho logístico são baseados em Ellram (1990); Lambert (1993); Coyle, Bardi e Langley (2003); Simatupang e Sridharan (2005); Vieira (2006); Vieira e Coutinho (2008), e Vieira e Machado (2008). Tais elementos se referem às entregas no tempo, entregas completas, entregas sem erro, entregas frequentes, disponibilidade de produto, cumprimento da agenda de entrega, cobertura de estoque e pedidos devolvidos. A este grupo dá-se o nome de critério qualificador de desempenho logístico. Como um dos elementos diferenciadores, pode-se citar o atendimento de pedido urgente ou em período de demanda alta. Estes são classificados nesta pesquisa como grupo dos elementos ganhadores de pedido, ou seja, é aquele que diferencia a empresa de seus concorrentes (SLACK et al., 1997).

\subsection{Elementos de custos de transação}

Segundo Williamson (1985), os custos são baseados em três dimensões da transação: especificidade de ativos, incerteza e frequência.

A especificidade de ativos tem como resultado o estabelecimento da relação de dependência entre as partes (HEIDE; JOHN, 1992), pois o valor do ativo depende da continuidade da transação da qual ele é específico. Assim, os custos de transação tendem a aumentar quando a especificidade de ativo aumenta (WILLIAMSON, 1985).

A utilização de ativos coespecializados (ou seja, ativos específicos que, quando juntos, têm maior influência ou valor na análise da transação do que separados) pode ser útil na análise de parcerias em uma cadeia de suprimentos (WILLIAMSON, 1985; NESHEIM, 2001) e pode contribuir para a relação de dependência bilateral que, por sua vez, tem influência na flexibilidade de troca de informação entre os agentes econômicos (LUSH; BROWN, 1996).

Dyer (1996) advoga que os custos de transação não necessariamente aumentam com os investimentos em ativos específicos realizados pelos parceiros. Segundo o autor, isso é possível porque as diferentes salvaguardas, que podem ser empregadas para reduzir o oportunismo, têm diferentes custos na construção de contratos e resultam em diferentes custos de transação, além de diferentes horizontes de tempo.

Dyer (1997) defende que a credibilidade investida nos relacionamentos colaborativos permite aumentar o número de transações. Ademais, maior intensidade no compartilhamento de informação e o emprego de leis autogerenciáveis permitem reduzir os custos de transação e aumentar o investimento em ativos específicos (Figura 2).

A incerteza pode ser definida como algo que proporciona insegurança e instabilidade às pessoas e ao ambiente da empresa (ROCHA, 2002). Ela está associada à informação assimétrica e incompleta, isto é, quando se reconhece a falta de informações importantes ao contrato, tornando-o, assim, incompleto e sujeito a atitudes oportunistas pelas 


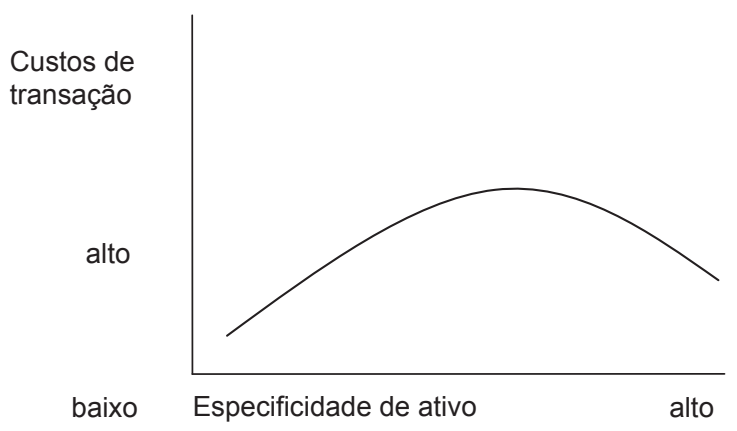

Figura 2. Custos de transação versus especificidade de ativos (firmas interdependentes). Fonte: Dyer, 1996.

partes envolvidas (FARINA et al., 1997). A incerteza contribui para aumentar a integração vertical, pois pode propiciar algum comportamento oportunista face aos distúrbios do mercado não facilitados pela contratação (ZYLBERSZTAJN, 1995), como no caso da disponibilidade de produtos sazonais, como no Natal, na Páscoa e em outras datas comemorativas. Nesse caso, alguns varejistas antecipam a compra desses produtos de forma a evitar a dependência do abastecimento pelo fornecedor nos picos de demanda. A incerteza está relacionada também à falta de confiança na relação. É importante salientar que a racionalidade limitada está relacionada à característica do indivíduo, enquanto a incerteza se aplica ao ambiente da transação. Assim, em ambiente onde os agentes buscam cumprir os acordos firmados, a confiança reduz as incertezas e novas contratações emergem. Portanto, o aumento da incerteza também elevaria os custos de transação (WILLIAMSON, 1985).

Quanto à frequência, as transações tendem a se repetir na ausência de ações oportunistas. Quanto maior a frequência, maior será a possibilidade de construção de reputação por partes dos agentes envolvidos na transação. Consequentemente, os custos de transação tendem a diminuir em valores relativos (não na mesma proporção do aumento da frequência), pois as partes se envolvem em mais ações conjuntas e constroem um ambiente de confiança e de reciprocidade. Logo, serão menores os custos ex-post, como monitoramento da transação, busca alternativa de parceiros para a mesma transação e fácil adaptação às novas regras (Figura 3).

Porém, espera-se que sempre haverá custos de transação, independentemente de aumento elevado da frequência, pois existe oportunismo, a racionalidade dos agentes é limitada e há incerteza do mercado (como realinhamento de preço) e de alguns ativos específicos relacionados anteriormente. A questão talvez seja reduzi-los ao máximo, de forma que tais custos sejam monitoráveis e não gerem custos de retrabalho elevados, como certos custos de coordenação das atividades logísticas (agendamento de docas em vários

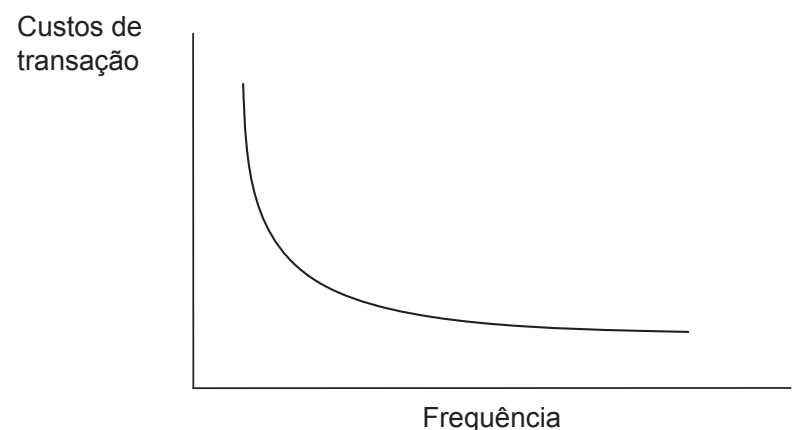

Figura 3. Frequências das transações em relação aos custos de transação. Fonte: elaborado pelos autores.

horários do dia, recebimento e expedição de mercadorias fora do horário, devoluções de carga, entre outros).

\section{Metodologia}

\subsection{Método}

A metodologia é composta por parcelas qualitativa e quantitativa, sendo o objeto de estudo a cadeia de abastecimento do varejo supermercadista, constituída neste caso por grandes redes de varejo e por indústrias fornecedoras de produtos (alimentos, eletroeletrônico, bazar, higiene e limpeza, bebidas e têxtil) para essas redes e também para atacadistas e distribuidores. A pesquisa qualitativa é composta de um estudo de caso e da observação participativa em uma das maiores redes de supermercado do país. Durante 11 meses, foram coletados dados por meio de reuniões, seminários e fóruns com a participação dos fornecedores, totalizando aproximadamente 250 horas. Algumas situações reais e depoimentos enriqueceram os resultados quantitativos gerados por esta pesquisa. A partir da pesquisa qualitativa, juntamente com o referencial teórico e pré-testes realizados em outras duas redes de varejo de médio porte e em um fornecedor de grande porte, foi possível elaborar o questionário final de pesquisa. Este foi aplicado a 125 representantes de 87 fornecedores de indústrias e permitiu elaborar as análises quantitativas.

\subsection{Amostra}

Primeiramente, deve-se destacar que a amostra da pesquisa quantitativa é composta por fornecedores (fabricantes) selecionados a partir de uma lista contendo todos os fornecedores da rede. Portanto, a amostra é por conveniência, porém também teve um caráter aleatório, pois, apesar de a lista de fornecedores partir de uma rede varejista (o que poderia influenciar a medida), as respostas eram dadas, na maioria das vezes (cerca de $80 \%$ ), em relação a outras grandes redes de varejo, além daquela (rede do estudo de caso). Ou seja, foi possível medir, de forma generalizada, 
a percepção que esses fornecedores têm em relação às maiores redes de supermercados. Ressalta-se que esses fornecedores são empresas de pequeno a grande porte, de diferentes regiões do território nacional e de diferentes origens de capital. A amostra da pesquisa qualitativa, além de considerar esses fornecedores (pois todos foram também entrevistados, o que gerou riqueza de dados), é composta também pela extensa observação participante com a equipe de logística da rede varejista. Os depoimentos possibilitaram coletar informações para subsidiar o estudo de caso, a construção do questionário e as conclusões preliminares que foram confirmadas pela pesquisa quantitativa.

A rede foi selecionada com base no critério intencional, pois permitiu livre acesso às reuniões de logísticas internas (com ou sem a presença de parceiros fornecedores) e externas (por meio de fóruns e visitas técnicas com os parceiros).

\subsection{Coleta de dados}

Aproveitando o espaço físico da rede varejista (do estudo de caso) e as reuniões mensais que a rede realizava com alguns de seus fornecedores, foi aplicado um questionário estruturado aos representantes dos fornecedores in loco, durante os meses de agosto a dezembro. Após tais reuniões, sem a presença de membros da referida rede, os pesquisadores solicitavam aos representantes que respondessem o questionário em relação a outro cliente, também de grande porte, dentre as oito maiores redes de supermercado presentes no Brasil. A duração das entrevistas variou entre uma hora e meia e quatro horas.

As respostas foram dadas pelos entrevistados da área de logística (que ocupavam cargos de analista, coordenador, supervisor, gerente e diretor) e não por empresas; assim, elas expressam a opinião de indivíduos. Na medida em que cada entrevistado avaliou uma rede de varejo diferente, as observações são independentes mesmo quando partiam de entrevistados da mesma empresa. Neste sentido, há dois fatores a considerar:

1) a diferença de percepção dos respondentes da mesma empresa pode revelar pontos fortes e fracos no relacionamento com parceiros diferentes; e

2) cada entrevistado pode trazer uma percepção diferente, dependendo do cargo ocupado na empresa e do tempo de casa.

\subsection{Questionário}

Foram utilizadas no questionário final (vide Anexo) duas formas de apresentação da escala. Na primeira, o respondente tinha uma escala visual de 0 a 10 , sendo a afirmativa nos dois lados extremos com sentidos opostos. Por exemplo, para a afirmativa "você colabora com o parceiro", no lado da nota zero, a palavra colaboração seria precedida pela palavra não; logo, ficaria "você não colabora com o parceiro". E no lado da nota dez, a palavra colaboração seria antecessora da palavra muito; logo, ficaria "você colabora muito com o parceiro". Este tipo de escala é interessante no sentido de alcançar maior atenção dos respondentes, porém eleva o tempo de resposta e a nota cinco pareceu ser uma tendência natural quando não se sabia o que responder. Na segunda forma de apresentação da escala, o respondente preenche com uma nota de 0 a 10 , sem precisar ter a escala visualmente. Esta escala é mais adequada para o respondente se sentir mais livre nas respostas e é mais rápida.

\subsection{Tratamento dos dados}

Segundo Barros e Lehfeld (2000), uma vez selecionados os dados para interpretação e análise, os passos seguintes são: classificação (tratamento ou agrupamento), codificação (categorização com letras ou números) e análise por meio de um tratamento estatístico. Neste sentido, utilizou-se o software Statistical Package for Social Study (SPSS), versão 12.0, como ferramenta de análise dos dados dos questionários. Esta ferramenta foi útil, pois possibilitou a realização de todas as análises estatísticas.

Vieira, Yoshizaki e Ho (2009) construíram, a partir da análise fatorial, fatores e índices que serviram para mensurar a intensidade de colaboração presente na transação fornecedor-varejista. Nesta pesquisa, por meio dos índices de colaboração, é feita a comparação entre os elementos de integração estratégica, tática e interpessoal, utilizando o teste $t$ simples e teste $t$ para dados emparelhados.

Os fatores são usados para medir o efeito que a colaboração exerce no desempenho logístico e nos custos de transação. Para isso, usou-se análise de regressão, sendo os fatores de colaboração, construídos a partir das variáveis do bloco 4 do questionário (Anexo), como as variáveis independentes (VIEIRA; YOSHIZAKI; HO, 2009); os fatores de desempenho logístico, construídos a partir das variáveis do bloco 5 do questionário (Anexo) e de custos de transação, construídos a partir das variáveis do bloco 6 do questionário (Anexo), como as variáveis dependentes (VIEIRA, 2006). As variáveis utilizadas estão assim definidas:

Variáveis dependentes:

- $\mathrm{DL}_{1}=$ Fator Desempenho Logístico Qualificador de Pedido;

- $\mathrm{DL}_{2}=$ Fator Desempenho Logístico Ganhador de Pedido;

- $\mathrm{CT}_{1}=$ Fator Custo de Transação (Fator Incerteza);

- $\mathrm{CT}_{2}=$ Fator Custo de Transação (Fator Especificidade de Ativo).

Variáveis independentes:

- $\mathrm{CO}_{1}=$ Fator Estratégico de Colaboração;

- $\mathrm{CO}_{2}=$ Fator Ações Conjuntas;

- $\mathrm{CO}_{3}=$ Fator Compartilhamento de Custos e Ganhos Logísticos;

- $\mathrm{CO}_{4}=$ Fator Compartilhamento de Informações Logísticas e Comerciais;

- $\mathrm{CO}_{5}=$ Fator de Colaboração Interpessoal. 


\section{Resultados e discussões}

\section{1 Índices de colaboração}

Esta análise revela conjuntos de elementos que os fornecedores julgam como mais importantes para a colaboração. Logo, é possível identificar o grau de intensidade de colaboração no elo fornecedor-rede varejista e, a partir daí, sugerir melhorias para incrementar o relacionamento entre os parceiros.

A Tabela 1 mostra as médias e desvios-padrão dos índices de colaboração.

Conforme a Tabela 1, os índices apresentam médias próximas de cinco. Considerando a escala de 0 a 10 , não se pode afirmar se esses valores são superiores ou inferiores a cinco, ou seja, se um determinado índice contribui para a maior ou menor intensidade de colaboração. Além disso, não se pode afirmar se um índice tem maior média do que o outro, ou seja, se há maior colaboração nos níveis estratégico, tático ou interpessoal.

Para verificar se determinados índices contribuem para uma maior intensidade de colaboração, foi testada a hipótese nula $\left(\mathrm{H}_{0}\right)$ : "a média de cada índice é igual a 5" por meio do teste $t$ (Tabela 2). Se a hipótese nula for rejeitada, há indicação de maior ou menor intensidade de colaboração.

Conforme indica a Tabela 2, o teste não foi significativo somente para o Índice COMP_CO3 (compartilhamento de custos e ganhos logísticos); como os demais apresentaram médias diferentes de cinco, logo a hipótese nula, para cada um dos quatro índices, é rejeitada. Verifica-se também que

Tabela 1. Média e desvios-padrão dos índices de colaboração.

\begin{tabular}{lcc}
\hline \multicolumn{1}{c}{ Índices de colaboração } & Médias & Desvio-padrão \\
\hline $\begin{array}{l}\text { Índice_CO5 - Relacionamento } \\
\text { interpessoal de colaboração - PES }\end{array}$ & 5,86 & 1,87 \\
$\begin{array}{l}\text { Índice_CO4 - Compartilhamento } \\
\text { de informações logísticas e } \\
\text { comerciais - INFO }\end{array}$ & 5,66 & 1,90 \\
$\begin{array}{l}\text { Índice_CO2 - Ações } \\
\text { conjuntas - CONJ }\end{array}$ & 5,49 & 1,96 \\
$\begin{array}{l}\text { Índice_CO1 - Nível estratégico de } \\
\text { colaboração - EST }\end{array}$ & 5,36 & 2,00 \\
$\begin{array}{l}\text { Índice_CO3 - Compartilhamento de } \\
\text { custos e ganhos logísticos - COMP }\end{array}$ & 4,84 & 1,95 \\
\hline
\end{tabular}

essas médias são superiores a cinco, pois o sinal da estatística do teste $t$ é positivo. Dessa forma, pode-se afirmar que esses índices contribuem para uma maior intensidade de colaboração e, portanto, representam um forte indicativo de que são importantes para maior colaboração entre os parceiros.

A coluna diferença das médias mostra que alguns índices apresentam maior média do que outros. Por exemplo: (índice interpessoal de colaboração) apresenta o valor de $0,864(5,864-5,0)$ que é quase o dobro do valor do EST_CO1 de 0,493 (5,493 - 5,0). Embora não se possa usar o teste $t$ (para amostra simples) para comparar duas variáveis, este resultado é um indicativo de que as informações de nível interpessoal têm maior intensidade e, portanto, contribuem mais para a colaboração do que as informações de nível estratégico.

No caso do Índice COMP_CO3, o estudo de caso mostrou que o aumento da frequência de entrega de pedido pelo fornecedor contribui para o aumento dos custos logísticos, pois o estoque é transferido do varejo para a indústria, embora se torne maior o conhecimento dos estoques do varejo.

No entanto, existem cláusulas logísticas previstas em contrato que têm o objetivo de regulamentar este compartilhamento de custos. Observou-se que os valores percentuais de tais cláusulas variam de parceiro para parceiro e que, dependendo do bom histórico de relacionamento, do bom desempenho logístico e da importância estratégica do parceiro (em termos de fatia de mercado para a rede), os valores contratuais são diferenciados. Isso não quer dizer que os custos contratuais sejam menores. Ou seja, os custos de construção dos contratos, embora não tenham sido medidos, são altos e se elevam à medida que aumenta o poder de barganha das empresas. Segundo um dos executivos de grande fornecedor: "temos este cliente como prioritário dentro da companhia, buscamos o melhor desempenho logístico, sempre procuramos um bom relacionamento, porém as negociações sempre são difíceis, por envolver altos volumes na transação".

Por outro lado, segundo o diretor de um fornecedor, muitas redes varejistas estão substituindo contratos formais por menores preços, para concorrer com os preços praticados por certas redes regionais e de bairros. Isto ocorre porque o contrato formal tem cláusulas explícitas que, se não forem cumpridas, incorre em multas para o fornecedor; consequentemente, a possibilidade de negociar menores

Tabela 2. Comparação das médias dos índices de colaboração em relação ao ponto central (5) da escala.

\begin{tabular}{lccccc}
\hline \multicolumn{1}{c}{ Índices } & Estatística t & Nível descritivo & Diferença das médias & Limite inferior & Limite superior \\
\hline EST_CO1 & 2,766 & 0,007 & 0,493 & 0,140 & 0,846 \\
CONJ_CO2 & 1,977 & 0,050 & 0,359 & 0,000 & 0,719 \\
COMP_CO3 & $-0,890$ & 0,375 & $-0,157$ & $-0,508$ & 0,193 \\
INFO_CO4 & 3,832 & 0,000 & 0,661 & 0,320 & 1,003 \\
PES_CO5 & 5,082 & 0,000 & 0,864 & 0,527 & 1,201 \\
121 graus de liberdade & & Valor de referência = 5 & Intervalo de confiança = 95\% \\
\hline
\end{tabular}


preços em troca de maior flexibilidade de entrega dos pedidos tem feito muitas redes varejistas de médio porte se tornarem concorrentes das redes de grande porte. Como relataram vários representantes industriais: “... do couro sai a correia. Ou seja, não adianta a grande rede varejista querer colocar tudo em contrato, pois qualquer adicional logístico a mais será embutido nos preços dos produtos".

Para comparar se um índice tem média maior do que o outro; utilizou-se o teste $t$ para dados emparelhados (Tabela 3).

Nesse sentido, foi feita uma comparação de pares de índices para melhor entendimento do grau de colaboração.

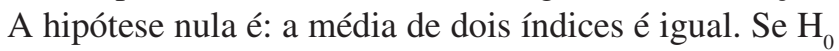
for rejeitada, pode-se dizer que um índice tem média maior ou menor do que o outro.

Os resultados da Tabela 3 indicam que a diferença das médias de todos os pares é diferente de zero. Ou seja, a hipótese nula é rejeitada. O EST_CO1 (índice estratégico de colaboração) tem menor média do que o PES_CO5 (índice interpessoal de colaboração), o que corrobora os resultados apresentados na Tabela 1: há evidência de que os parceiros acreditam nas trocas, têm valores que são interdependentes e são flexíveis às mudanças operacionais mais do que compartilham as informações de seus estoques e operações de produção.

Os três índices que formam a integração tática, como descrito na revisão da literatura, são: CONJ_CO2 (ações conjuntas), COMP_CO3 (compartilhamento de custos e ganhos logísticos) e o INFO_CO4 (compartilhamento de informações logísticas e comerciais). A Tabela 3 mostra a comparação das médias desses índices (integração tática) com o EST_CO1 (Índice estratégico de colaboração). A análise da relação EST_CO1 × COMP_CO3 indica que EST_CO1 tem maior média do que COMP_CO3. Assim, há evidência de que a indústria compartilha com o varejo mais informações estratégicas do que custos e ganhos logísticos. A análise da relação EST_CO1 $\times$ CONJ_CO2 revela que EST_CO1 também tem maior média do que CONJ_CO2: há evidência de que os parceiros compartilham mais informações de estoque e conhecem mais as dificuldades logísticas um do outro do que participam de ações conjuntas, como desenvolver projetos conjuntos, envolver as áreas funcionais das duas empresas e ter equipe dedicada para atendimento do parceiro. Por outro lado, a análise da relação EST_CO1 × INFO_CO4 revela que EST_CO1 tem menor média do que INFO_CO4; isto indica que a indústria compartilha mais informações logísticas e comerciais do que estratégicas.

Na Tabela 3, todos os índices que compõem a integração tática (CONJ_CO2, COMP_CO3 e INFO_CO4), quando comparados com PES_CO5 (índice interpessoal de colaboração), têm médias menores do que este. Ou seja, a indústria dá maior importância aos elementos de integração interpessoal (como confiança, reciprocidade, flexibilidade e interdependência) do que aos elementos de integração tática (como as ações conjuntas, o compartilhamento de informação logística e comercial e o compartilhamento de custos e ganhos logísticos). A Figura 4 resume estes resultados.

Observa-se que a colaboração interpessoal, baseada em confiança, reciprocidade, flexibilidade, comprometimento e interdependência, é mais importante para ganhos colaborativos. Isso indica que a colaboração interpessoal tende a conduzir a uma maior parceria ou integração,

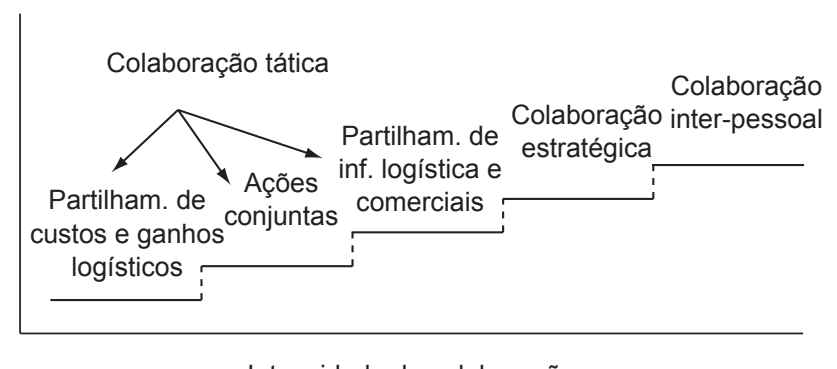

Intensidade de colaboração

Figura 4. Intensidade de colaboração segundo os índices de colaboração.

Tabela 3. Médias dos índices emparelhados.

\begin{tabular}{|c|c|c|c|c|c|}
\hline \multirow[t]{2}{*}{ Pares de índices } & \multirow[t]{2}{*}{ Estatística t } & \multirow[t]{2}{*}{ Nível descritivo } & \multirow[t]{2}{*}{ Médias } & \multicolumn{2}{|c|}{ Diferença entreduas médias } \\
\hline & & & & Limite inferior & Limite superior \\
\hline CONJ_CO2 $\times$ EST_CO1 & $-2,009$ & 0,047 & $-0,134$ & $-0,266$ & $-0,002$ \\
\hline COMP_CO3 ×EST_CO1 & $-7,125$ & 0,000 & $-0,651$ & $-0,831$ & $-0,470$ \\
\hline INFO_CO4 ×EST_CO1 & 2,628 & 0,010 & 0,168 & 0,042 & 0,295 \\
\hline PES_CO5 ×EST_CO1 & 5,985 & 0,000 & 0,371 & 0,248 & 0,494 \\
\hline CONJ_CO2 $\times$ COMP_CO3 & 5,843 & 0,000 & 0,517 & 0,342 & 0,692 \\
\hline CONJ_CO2 × INFO_CO4 & $-3,528$ & 0,001 & $-0,302$ & $-0,472$ & $-0,133$ \\
\hline CONJ_CO2 × PES_CO5 & $-9,252$ & 0,000 & $-0,505$ & $-0,613$ & $-0,397$ \\
\hline INFO_CO4 × COMP_CO3 & 9,076 & 0,000 & 0,819 & 0,640 & 0,997 \\
\hline PES_CO5 ×COMP_CO3 & 13,191 & 0,000 & 1,021 & 0,868 & 1,175 \\
\hline INFO_CO4 × PES_CO5 & $-2,817$ & 0,006 & $-0,203$ & $-0,345$ & $-0,060$ \\
\hline 121 graus de liberdade & \multicolumn{5}{|c|}{ Intervalo de confiança $=95 \%$} \\
\hline
\end{tabular}

Fonte: Vieira, Yoshizaki e Ho (2009). 
produzindo resultados mais duradouros e maior eficiência logística, enquanto a colaboração tática ocorre primordialmente apenas na coordenação das atividades logísticas. O compartilhamento de custos e ganhos logísticos, apesar de ser muito importante, desperta, na prática atual brasileira, pouco interesse dos agentes. Parece ser mais eficiente o varejo cobrar multas por atraso na entrega do pedido ou este ser entregue incompleto. Segundo um entrevistado da área do varejo: “... as multas não têm a intenção de punir ou cobrar do fornecedor uma quantia a mais. Elas existem para resguardar ruptura, por causa dos atrasos e falta de produtos...".

Por outro lado, um gerente de um fornecedor diz: “...se estamos em uma reunião que se discute colaboração, não deveria existir este tipo de ação ...". No entanto, segundo o gerente de logística da rede varejista, desde a aplicação das multas, a ruptura no Centro de Distribuição (CD) reduziu de 29 para $13 \%$ ao mês.

Por fim, pela Figura 4, pode-se inferir que os gestores constroem relações pessoais e estratégicas (baseadas no conhecimento e no histórico de relacionamento/envolvimento da alta gerência) antes de estabelecer relações comerciais com os parceiros de negócio.

\subsection{Associação entre colaboração e desempenho logístico}

Foi testada a influência que a colaboração pode exercer no desempenho logístico do fornecedor. Há várias situações em que a colaboração ora produz resultados positivos para o desempenho logístico, ora é indiferente para a melhora do atendimento do nível de serviço ao cliente. Neste sentido, procurou-se testar o efeito da colaboração em dois fatores de desempenho logístico: o fator de desempenho logístico qualificador - DL1 (composto por elementos mais comuns de mensuração dos índices logísticos) e o fator de desempenho logístico ganhador de pedido - DL2 (composto por elementos de diferenciação na medição dos índices logísticos), como descrito na revisão de literatura. A Tabela 4 apresenta os resultados das análises de regressões envolvendo colaboração e desempenho logístico.

Observa-se pela Tabela 4 um melhor ajustamento para a segunda regressão (DL2), que apresentou um coeficiente de determinação $\mathrm{R}^{2}$ de $38 \%$ e o teste $F$ significativo a $1 \%$. Na primeira regressão (DL1), o coeficiente de determinação $R^{2}$ é muito menor e o teste $F$ significativo a $10 \%$. Desta forma, será apresentada uma análise qualitativa (por meio do estudo de caso) para o DL1 e detalhada a análise quantitativa somente do DL2 como variável resposta, ou seja, a influência da colaboração no desempenho logístico em que as entregas são em períodos de demanda alta e urgentes.

Na análise do DL1, observou-se que as ações conjuntas e o relacionamento interpessoal são fundamentais para um melhor desempenho logístico. O programa colaborativo da rede varejista com os seus fornecedores apresenta vários pontos positivos, segundo a equipe do varejo: houve maior padronização da linguagem e da comunicação entre as equipes de logística; ocorreu melhor visualização de novos projetos; facilitou-se o relacionamento estratégico com fornecedores; estimulou-se a equipe na busca de novos conhecimentos e desafios logísticos, como projetos (carregamento de retorno, VMI, cross-docking, entre outros); existiu maior desenvolvimento de novos processos logísticos e alinhamento entre as equipes de logística e de apoio; proporcionou um referencial entre os fornecedores, e estimulou a eficiência destes. Quando os pedidos são originados da região Norte do país (produtos eletroeletrônicos) ou da região Sul (commodities, como arroz), os custos logísticos aumentam com o alinhamento entre as áreas funcionais das empresas, pois a devolução desses pedidos - como por indisponibilidade de mão de obra para descarga, erros na nota fiscal ou falta de agendamento - geram baixos índices de desempenho logístico por não se adequarem às exigências da rede varejista. Segundo um coordenador do varejo: “....a distância aumenta o meu estoque de segurança. Se o serviço do concorrente é melhor, tenho que buscar novas alternativas para reduzir os meus custos com esses estoques".

Segundo um gerente de um fornecedor: “... a falta de alinhamento e ações conjuntas entre as áreas das duas empresas onera os nossos custos, pois fazemos o mesmo trabalho duas ou mais vezes e ainda não resolvemos os problemas. O alinhamento deve existir sempre..."

Em relação ao DL2, nota-se que todos os coeficientes são positivos e, portanto, a maior intensidade de colaboração resulta na melhora do desempenho logístico. A Tabela 4 também mostra (pelo teste $F$ ) que os fatores conjuntamente explicam a variável dependente (DL2).

\subsection{Associação entre colaboração e custo de transação}

Os custos de transação foram separados em dois fatores: o fator incerteza (CT1) e o fator especificidade de ativo (CT2). A dimensão frequência foi analisada indiretamente por meio do estudo de caso. Este mostrou que uma maior intensidade de colaboração contribui para aumentar a frequência de entrega: consequentemente, seu aumento leva a transações recorrentes e duradouras. $\mathrm{O}$ fator incerteza foi analisado por meio das variáveis: renegociação de contratos, tempo de espera para resoluções de contingências logísticas e tempo para negociação de novos acordos logísticos. Nesse sentido, espera-se que a colaboração tenha um efeito negativo na incerteza organizacional, já que os parceiros buscam ações conjuntas no sentido de melhorar o desempenho logístico.

A Tabela 5 mostra o resultado do modelo de regressão composta pelos fatores de colaboração. 
Observa-se pela Tabela 5 que apenas o coeficiente de $\mathrm{CO} 2$ (fator ações conjuntas) e o coeficiente de CO5 (fator interpessoal de colaboração) são estatisticamente significativos. Este resultado pode ser explicado pelo constante envolvimento dos parceiros na resolução de contingências logísticas (atraso de entrega, devolução de produtos, entre outros problemas com pedidos) e pelo contato direto nas negociações de contrato e efetivação de novos acordos logísticos.

Por outro lado, o estudo de caso revelou que a demora nas negociações de contrato e efetivação de novos acordos logísticos pode envolver elevados custos de transação. Até que se chegue a um acordo entre as partes, o custo de venda perdida e o próprio custo de contrato (elaboração de novas regras, tempo despendido em reuniões, entre outros) podem contribuir para uma diminuição da transação entre a rede varejista e este fornecedor, ou prejudicar o desempenho logístico, pois a falta de acordo gera desconfiança e desinteresse em atender aos pedidos com os níveis de serviço desejáveis. Segundo um gerente de um fornecedor: "Nós ficamos cinco meses negociando o acordo anual e, durante este tempo, os nossos produtos, que são os mais procurados dentro da categoria, ficaram em falta (chegamos a entregar um item enquanto que a nossa carteira para este cliente é de 700 itens). Diante da falta de acordo, o nosso desempenho logístico foi baixíssimo, pois nunca se formava carga que compensasse a entrega dos produtos, o que acarretava pedido não entregue ou pedido entregue incompleto".

No entanto, não se pode afirmar que a colaboração tenha um efeito negativo na incerteza, pois era de se esperar que os outros fatores de colaboração também fossem significativos. Por exemplo, o coeficiente de compartilhamento de informações logísticas e comerciais - que tem interpretação semelhante ao fator de ações conjuntas no sentido de ter interação entre as áreas de logísticas e comerciais das empresas -, deveria também ser negativamente correlacionado. Logo, não se pode afirmar que a colaboração produz um efeito significativo no fator incerteza, que compõe os custos de transação.
As incertezas são mais evidentes ainda quando os fornecedores são pequenos. Neste caso, alguns fornecedores que têm operações dedicadas à rede varejista, às vezes, deixam de atender aos pedidos de outros clientes para manter o bom nível de serviço àquela rede. Porém, isso acarreta custos extras com armazenagem, custos com compra antecipada de material, custos com produção dedicada e custos decorrentes da incerteza da relação (postergação de entrega, ajustes em renegociações, reescrita de contratos, entre outros).

O fator especificidade de ativo (composto pelos elementos especificidade de ativo humano e ativo físico) está associado ao grau de investimento que as indústrias têm no relacionamento com o parceiro. A Tabela 6 mostra os resultados da análise de regressão dos fatores de colaboração e o fator especificidade de ativo.

Apenas dois fatores apresentaram resultados significativos, cujos coeficientes são positivos. Ou seja, o aumento do grau de colaboração decorrente destes fatores contribui para o aumento de investimento em ativos específicos. Este investimento em ativos específicos tende a tornar os relacionamentos mais fechados, pois faz com que as indústrias tenham serviços ou produtos direcionados para determinados clientes varejistas, como, por exemplos, entrega e equipe dedicada. No entanto, o aumento desse custo pode ser compensado pelo aumento do volume de vendas, pelo

Tabela 5. Modelo geral estimado para o fator incerteza em relação à colaboração.

\begin{tabular}{lcc}
\hline \multicolumn{3}{c}{ Variável dependente - Fator incerteza - CT1 } \\
\hline \multicolumn{1}{c}{ Variáveis independentes } & Coeficientes & T \\
\hline CO2 - Fator ações conjuntas & $-0,351$ & $-3,761 *$ \\
CO5 - Fator interpessoal de & $-0,191$ & $-2,064 * *$ \\
colaboração & & \\
$\mathrm{R}^{2}$ ajustado. $=0,15 ; \mathrm{F}=9,84 *$ & \\
\hline Nota: * significância a 1\%; ** a 5\%. Todos os coeficientes são \\
padronizados.
\end{tabular}

Tabela 4. Modelo geral estimado para o desempenho logístico para toda a amostra.

\begin{tabular}{|c|c|c|c|}
\hline \multicolumn{4}{|c|}{ Variável dependente - Fator qualificador de desempenho - DL1 } \\
\hline Variáveis explicativas & Coeficientes & $\mathbf{t}$ & Demais estatísticas \\
\hline $\mathrm{CO} 2$ - Fator ações conjuntas & 0,181 & $2,043 * *$ & $\mathrm{R}^{2}$ ajustado $=0,06$ \\
\hline CO5 - Fator interpessoal de colaboração & 0,205 & $2,309 * *$ & $\mathrm{~F}=4,75^{*} *$ \\
\hline \multicolumn{4}{|c|}{$\begin{array}{l}\text { Variável dependente - Fator ganhador de pedido de desempenho - DL2 } \\
\end{array}$} \\
\hline Variáveis explicativas & Coeficientes & $\mathbf{t}$ & Demais estatísticas \\
\hline CO1 - Fator estratégico de colaboração & 0,121 & $1,721 * *$ & $\mathrm{R}^{2}$ ajustado $=0,38$ \\
\hline $\mathrm{CO} 2$ - Fator ações conjuntas & 0,163 & $2,267 * *$ & \\
\hline CO3 - Fator compart. de custos e ganhos logísticos & 0,119 & $1,759 * *$ & $\mathrm{~F}=15,67 *$ \\
\hline CO4 - Fator compart. de inf. comerciais e logísticas & 0,277 & $3,845^{*}$ & \\
\hline CO5 - Fator interpessoal de colaboração & 0,523 & $7,269 *$ & \\
\hline
\end{tabular}

Nota: * significância a $1 \%$; ** a $5 \%$. Todos os coeficientes são padronizados. 
Tabela 6. Modelo geral para o fator especificidade de ativo em relação à colaboração.

\begin{tabular}{lccc}
\hline \multicolumn{3}{c}{ Variável dependente - fator especificidade de ativo-CT2 } \\
\hline Variáveis explicativas & Coeficientes & $\mathbf{T}$ & $\begin{array}{c}\text { Demais } \\
\text { estatísticas }\end{array}$ \\
\hline $\begin{array}{l}\text { CO1 - Fator estratégico } \\
\text { de colaboração }\end{array}$ & 0,306 & $3,497^{*}$ & $\mathrm{R}^{2}$ ajustado. $=0,21$ \\
$\begin{array}{l}\text { CO2 - Fator ações } \\
\text { conjuntas }\end{array}$ & 0,352 & $4,019^{*}$ & $\mathrm{~F}=14,95^{*}$ \\
\hline
\end{tabular}

Nota: *significância a 1\%;** a 5\%. Todos os coeficientes são padronizados.

comprometimento entre as partes e pela facilidade em se adequar às exigências dos clientes varejistas, pois já se conhecem as "regras do jogo". Segundo um gerente de um pequeno fornecedor: "tenho linhas dedicadas a grandes redes, pois são eles que garantem o maior volume de produção e que nos mantêm atualizados e em busca de padronização de nossos processos de produção e de entrega".

Os resultados mostraram que apenas alguns fatores de colaboração contribuem para diminuição da incerteza e que outros fatores contribuem para o aumento da especificidade de ativo entre os participantes; porém, não há convergência nos resultados, ou seja, se na presença de colaboração os custos de transação são reduzidos. Há, portanto, necessidade de maiores estudos neste sentido.

\section{Conclusões e implicações gerenciais}

A pesquisa aplicada mostrou que a colaboração pode ser considerada composta por três tipos de integração: estratégica, tática e interpessoal. Esta última se apresenta com maior intensidade em relação às demais. Logo, a colaboração interpessoal - com base em confiança, interdependência, reciprocidade e flexibilidade - deve ser tratada prioritariamente entre os parceiros. Além disso, há um hiato entre colaborar estrategicamente e compartilhar custos e ganhos logísticos. Assim, a construção de projetos de longo prazo pode promover maior interdependência entre as partes e contribuir para maior intensidade de colaboração não só estratégica como também colaboração tática (ações conjuntas, compartilhamento de informações e custos e ganhos logísticos). Por meio dessas ações conjuntas, talvez seja possível estreitar as relações entre as equipes envolvidas, na busca de melhor padronização e documentação dos processos, além de aumentar a credibilidade das ações diárias. Por outro lado, desenvolver a confiança interpessoal entre as partes pode facilitar a negociação de contratos de longo prazo e reduzir o tempo de espera na efetivação dos acordos ou projetos logísticos.

Foi visto também que a colaboração contribui para melhorar o desempenho logístico, no que tange às entregas urgentes e entregas em período de demanda alta. Isso indica que uma relação mais próxima entre os parceiros promove menor incerteza, maior comprometimento e interdependência, com um possível aumento de investimento em ativos específicos. O custo com estes investimentos pode ser compensado pelo aumento do volume de contratação.

Quanto aos custos de transação, conclui-se que maior colaboração interpessoal e das ações conjuntas contribui para reduzir as incertezas entre os participantes e que essas ações conjuntas, juntamente com a colaboração estratégica, contribuem para incrementar o investimento em ativos específicos, como implantação de linhas dedicadas ou frotas de veículos para atendimento do parceiro.

As limitações da pesquisa são: a) a análise está restrita ao ponto de vista dos fornecedores em relação às grandes redes de varejo supermercadista, o que não permite generalizar as análises para mercado do varejo como um todo; e b) a pesquisa quantitativa foi realizada a partir de uma lista usada pela rede varejista para tratar dos acordos colaborativos. Logo, mesmo que os entrevistados tenham respondido à pesquisa referenciando outras grandes redes de varejo, alguns questionários podem ter sido preenchidos em relação à rede varejista do estudo de caso, podendo haver vieses.

Como sugestões de trabalhos futuros se destacam: a) analisar as causalidades entre colaboração e desempenho logístico, e colaboração e custos de transação; e b) avaliar práticas de colaboração, aos pares e durante um maior tempo de parceria, em especial alguns acordos colaborativos muito citados pela indústria, como cross-docking, Vendor Managed Inventory (VMI) e Collaborative Planning, Forecasting and Replenishment (CPFR). 


\section{The collaborative logistic study between cpg industry and retail market}

\section{Abstract}

This paper aims to ascertain the current state of collaborative logistics in the Brazilian supermarket retail chain through two quantitative studies: one concerning collaboration elements and logistics performance, and the other quantitative study focusing on collaboration elements and transaction costs. All of these elements are identified among the partners. The methodology consists of a qualitative analysis (using participative observations) and a quantitative analysis consisting of 125 representatives from 87 suppliers who evaluated Brazil's four largest retailers. From statistical tests and regression analysis, the results confirmed that some collaborative elements positively influence the logistics performance of the firms, mainly when it concerns a differentiated logistic performance (urgent deliveries and deliveries in periods of high demand). Interpersonal integration contributes most to a higher intensity of collaboration, followed by strategic integration and tactical integration. Moreover, the increase in strategic collaboration and joint actions (tactical integration elements) contributes to the reduction in uncertainties between the participants and these joint actions also help to increase investment in specific assets.

Key words: Collaboration elements. Logistic performance. Transaction costs. Retail.

\section{Referências bibliográficas}

ANDERSON, J. C.; NARUS, J. A. A model of distributor firm and manufacturer firm working partnerships. Journal of Marketing, v. 54 , p. $42-58,1990$

BARRATT, M. Understanding the meaning of collaboration in the supply chain. Supply Chain Management: An International Journal, v. 9, n. 1, p. 30-42, 2004.

BARROS, A. J. S.; LEHFELD, N. S. Fundamentos de metodologia científica: uma guia para a iniciação científica. 2 ed. São Paulo: Makron Books, 2000. 84 p.

BOWERSOX, D. J.; CLOSS, D. J.; COOPER, M. B. Gestão logística de cadeias de suprimento. Porto Alegre: Bookman, 2006. 529 p.

CHOI, T. Y. et al. Supplier-supplier relationships and their implications for buyer-supplier relationships. IEEE Transaction on Engineering Management, v. 49, n. 2, p. 119-129, 2002.

COYLE, J. J.; BARDI, E. J.; LANGLEY Jr., C. J. The Management of Business Logistics: A Supply Chain Perspective. 7 ed. Ohio: Thompson Learning, 2003. 707 p.

DYER, J. H. Does governance matter? Keiretsu alliances and asset specificity as sources of Japanese competitive advantage. Organization Science, v. 7, n. 6, p. 649-666, 1996.

DYER, J. H. Effective interfirm collaboration: how firms minimize transaction costs and maximize transaction value. Strategic Management Journal, v. 18, n. 7, p. 535-556, 1997.

ELLRAM, L. M. International supply chain management: strategic implications for the purchasing function. Ohio, 1990. 343 p. Dissertation (Doctor of Philosophy) - Graduate School of the Ohio State University.

FARINA, E. M. M. Q.; AZEVEDO, P. F.; SAES, M. S. M. Competitividade: mercado, estado e organizações. São Paulo: Singular, 1997. 286 p.

FROHLIC, M. T.; WESTBROOK, R. Arcs of integration: an international study of supply chain strategies. Journal of Operations Management, v. 19, p. 185-200, 2001.

HEIDE, J. B.; JOHN, G. Do norms matter in marketing relationships? Journal of Marketing, v. 56, n. 2, p. 32-44, 1992.

KANTER, R. M. Collaborative Advantage: The art of alliances. Harvard Business Review, Jul-Ago, p. 96-108, 1994.
KIM, K. On determinants of joint action in industrial distributor supplier relationships: beyond economic efficiency. Journal of Marketing, v. 16, p. 217-236, July 1999.

LAMBERT, D. M. Developing a customer-focused logistics strategy. International Journal of Physical Distribution and Logistics Management, v. 23, n. 6, p. 12-19, 1993.

LUSH, R. F.; BROWN, J. R. Interdependency, contracting, and relational behavior in marketing channels. Journal of Marketing, v. 60, n. 4, p. 19-38, 1996.

NESHEIM, T. Externalization of the core: antecedents of collaborative relationships in clothing supply chains. European Journal of Purchasing and Supply Management, v. 7, p. 217-225, 2001

PAVAN, F. M.; PIRES, S. R. I. Medição de desempenho na gestão da cadeia de suprimentos: uma proposta de indicadores de desempenho baseados no modelo SCORE e nas dimensões competitivas da manufatura. In: ENCONTRONO NACIONAL DE ENGENHARIA DE PRODUÇÃO, 24, 2004, Florianópolis. Anais... Florianópolis: Novodisc Mídia digital, 2004.

POPP, R. Swamped in information, but starved of data: information and intermediaries in clothing supply chains. Supply Chain Management Review, v. 5, n. 3, p. 28-36, 2000.

ROCHA, M. M. Integração vertical e incerteza. São Paulo, 2002. $159 \mathrm{f}$. Tese (Doutorado em Economia) - Faculdade de Economia, Administração e Contabilidade, Universidade de São Paulo.

SIMATUPANG, T. M.; SRIDHARAN, R. The collaborative supply chain. International Journal of Logistics Management, v. 3, n. 1, p. 15-30, 2002.

SIMATUPANG, T. M.; SRIDHARAN, R. The collaboration index: a measure for supply chain collaboration. International Journal of Physical Distribution \& Logistics Management, v. 35, n. 1, p. 44-62, 2005.

SLACK, S. et al. 1997. Administração da Produção. São Paulo: Atlas, 1997. $726 \mathrm{p}$.

VIEIRA, J. G. V. Avaliação do estado de colaboração logística entre indústria de bens de consumo e redes de varejo supermercadista. 
São Paulo, 2006. 207 f. Tese (Doutorado em Engenharia de Produção) - Escola Politécnica, Universidade de São Paulo.

VIEIRA, J. G. V.; COUTINHO, D. P. Avaliação da colaboração logística entre uma distribuidora e seus fornecedores. Revista Eletrônica Produção \& Engenharia, v. 1, n. 1, p. 53-68, 2008. Disponível em: http://www.revistaproducaoengenharia.org/ artigos/109_53.pdf. Acesso em: 10 Novembro 2008.

VIEIRA, J. G. V; MACHADO, V. R. Colaboração logística: um estudo entre supermercados de pequeno e médio porte e seus fornecedores. GEPROS - Gestão da Produção, Operações e Sistemas, ano 3, n. 2, p. 89-103, Abr-Jun, 2008.

VIEIRA, J. G. V.; YIOSHIZAKI, H. T. Y.; HO, L. L. Collaboration intensity in the Brazilian supermarket retail chain. Supply Chain Management: an International Journal Review, v. 4, n. 1, p.11-21, January 2009.
VIEIRA, J. G. V.; YOSHIZAKI, H. T. Y.; LUSTOSA, L. J. Um estudo exploratório sobre colaboração logística num grande varejo supermercadista. Revista Produção. 2010. [no prelo].

WILDING, R.; HUMPHIRES, A. S. Understanding collaborative supply chain relationships through the application of the Williamson organizational failure framework. International Journal of Physical Distribution and Logistics Management, v. 26, n. 4, p. 309-329, 2006.

WILLIAMSON, O. E. The Economic Institutions of Capitalism. New York: The Free Press, 1985. 450 p.

ZYLBERSZTAJN, D. Estruturas de Governança e Cooperação do Agribusiness: uma aplicação da Nova Economia das Instituições. São Paulo, 1995. 236 f. Tese (Livre Docência) - Faculdade de Economia, Administração e Contabilidade, Universidade de São Paulo.

\section{Sobre os autores}

\section{José Geraldo Vidal Vieira}

Departamento de Engenharia de Produção - Campus Sorocaba

Universidade Federal de São Carlos - UFSCar

Rodovia João Leme dos Santos (SP-264), Km 110, Bairro Itinga, CEP 18052-780, Sorocaba - SP, Brasil

e-mail: jose-vidal@ ufscar.br

\section{Hugo Tsugunobu Yoshida Yoshizaki}

Departamento de Engenharia de Produção

Escola Politécnica da Universidade de São Paulo - EPUSP

Av. Prof. Almeida Prado, Travessa 2, 128, CEP 05508-900, São Paulo - SP, Brasil

e-mail: hugo@usp.br

\section{Linda Lee Ho}

Departamento de Engenharia de Produção

Escola Politécnica da Universidade de São Paulo - EPUSP

Av. Prof. Almeida Prado, Travessa 2, 128, CEP 05508-900, São Paulo - SP, Brasil

e-mail: lindalee@usp.br

Agradecimento: Os autores agradecem à CAPES pelo financiamento parcial desta pesquisa. 


\section{Anexo}

\section{Questionário de pesquisa modificado de Vieira (2006)}

Bloco 1. Caracterização da indústria.

\begin{tabular}{|l|l|}
\hline Nome da empresa: & \\
\hline Entrevistado/e-mail: & \\
\hline Cargo/fone: & \\
\hline
\end{tabular}

1. Qual o principal setor de atuação da empresa (em termos de faturamento)?

\begin{tabular}{|l|l|l|l|}
\hline & Alimentar não perecíveis tipo commodities & Higiene e limpeza \\
\hline & Alimentar não perecíveis (seca) & & Eletro-eletrônico \\
\hline & Têxtil: & & Bebidas \\
\hline & Bazar: & & Outros: \\
\hline
\end{tabular}

2. Capital de origem da empresa.

\begin{tabular}{|l|l|l|l|}
\hline & Nacional & & Não-nacional \\
\hline
\end{tabular}

3. Localização da empresa (principal centro de origem para distribuição dos produtos do setor).

\begin{tabular}{|l|l|l|l|}
\hline & Grande São Paulo & & Fora da Grande São Paulo \\
\hline
\end{tabular}

4. Número de funcionários

\begin{tabular}{|l|l|l|l|}
\hline & Até 50 & & De 201 a 500 \\
\hline & De 51 a 200 & & Acima de 500 \\
\hline
\end{tabular}

5. Faturamento anual da empresa (em milhões de reais):

Bloco 2. Caracterização do varejo.

Escolha um cliente varejista (rede de supermercado) que esteja entre os oito maiores para a sua empresa. Marque abaixo qual a posição que este varejo representa.

\begin{tabular}{|c|c|c|c|c|c|c|}
\hline$\square$ & $\square$ & $\square$ & $\square$ & $\square$ & $\square$ & $\square$ \\
\hline $1^{\mathrm{o}}$ & $2^{\circ}$ & $3^{\circ}$ & $4^{\circ}$ & $5^{\circ}$ & $6^{\circ}$ & $7^{\circ}$ \\
\hline
\end{tabular}

6. Capital de origem do parceiro.

\begin{tabular}{|l|l|l|l|}
\hline & Nacional & & Não nacional \\
\hline
\end{tabular}

\section{Responda todas as questões seguintes sempre referindo a este parceiro}

Bloco 3. Caracterização do relacionamento indústria e varejo.

7. Qual o volume de vendas (em percentagem), em relação às vendas totais da empresa, para este parceiro? Ou seja, qual a participação deste parceiro dentro da empresa.

8. Qual o número de SKU's vendido para este parceiro? Considere os produtos do setor escolhido.

9. Qual a frequência de entrega de pedidos?
$\square$ Diária
$\square$ Duas vezes por semana
Três vezes por semana
$\square$ Semanal
$\square$ Quinzenal
Mensal

Gest. Prod., São Carlos, v. 16, n. 4, p. 556-570, out.-dez. 2009 
Anexo. Continuação...

10. Qual é o prazo de entrega dos produtos para este parceiro? Considere sempre a distância do seu principal centro de distribuição (dos produtos do setor escolhido) e o principal local (responsável pelo maior volume ou venda) para a entrega dos produtos.
1 a 2 dias
3 a 5 dias
6 a 9 dias
10 a 15 dias
Acima de 15 dias

11. Qual a proximidade entre as empresas $(\mathrm{km})$ para entrega dos produtos? Considere sempre a distância do seu principal centro de distribuição (dos produtos do setor escolhido) e o seu parceiro.

12. O histórico de relacionamento com o meu parceiro nos últimos 2 anos é:
Ruim
0
2
34
567
$\begin{array}{llll}7 & 8 & 9 & 10\end{array}$
Ótimo

\section{As questões seguintes se referem ao grau de colaboração com o parceiro}

Bloco 4. Colaboração com o parceiro.

13. Como eu avalio o grau de colaboração da minha empresa com o meu parceiro em relação às variáveis seguintes.

Dê uma nota de 0 a 10 .

\begin{tabular}{|c|}
\hline Compartilhamento de informação do nível de estoque (das duas empresas) \\
\hline Compartilhamento de metas e planos de negócio conjunto \\
\hline Envolvimento da alta gerência ou diretoria (das duas empresas) nos projetos de logística \\
\hline Participação das equipes em conjunto (das duas empresas) nos processos logísticos \\
\hline Criação de novos projetos logísticos em conjunto \\
\hline Conhecimento das dificuldades e estratégias do meu parceiro \\
\hline Envolvimento de uma pessoa ou equipe dedicada por projeto com o parceiro \\
\hline Utilização de sistema de informação para troca automática de dados \\
\hline Planejamento conjunto de pedido \\
\hline Transparência na comunicação entre os parceiros para resolução de contingências \\
\hline Planejamento conjunto de sortimento de produtos \\
\hline Compartilhamento de informação na troca de previsão de vendas \\
\hline Compartilhamento de informação dos dados de ponto de venda \\
\hline Compartilhamento de informação de eventos promocionais \\
\hline Planejamento conjunto de eventos promocionais \\
\hline Compartilhamento de custos para identificação de causas de ruptura de gôndola \\
\hline Compartilhamento dos custos de entrega \\
\hline Compartilhamento dos custos com devolução de produto \\
\hline Compartilhamento dos ganhos logísticos \\
\hline Compartilhamento dos riscos (roubo, avarias, acidentes) \\
\hline Interdependência (importância de um para o outro) na relação \\
\hline Confiança no parceiro \\
\hline Flexibilidade de mudança de parâmetro logístico (das duas empresas) \\
\hline Grau de reciprocidade (dar e receber em troca) na relação com o parceiro \\
\hline Grau de participação conjunta em seminários, congressos e comitês da área \\
\hline
\end{tabular}




\section{As questões seguintes se referem ao meu desempenho logístico com o parceiro}

Bloco 5. Desempenho logístico.

14. Como eu avalio o meu desempenho logístico (nos últimos 2 anos) em relação às variáveis seguintes. Dê uma nota de 0 a 10 . Dez é quando eu tenho o melhor desempenho logístico.

\begin{tabular}{|l|l|}
\hline & Entregas na data prometida (após o pedido) \\
\hline & Entregas completas \\
\hline & Entregas sem erro \\
\hline & Ruptura de gôndola. Se a ruptura é alta, a nota é zero \\
\hline & Cobertura de estoque do parceiro (loja ou CD) \\
\hline & Disponibilidade de produto para o parceiro \\
\hline & Atendimento de pedido em período de demanda alta \\
\hline & Cumprimento da agenda de entrega \\
\hline & Pedidos devolvidos \\
\hline & Entregas frequentes \\
\hline
\end{tabular}

Bloco 6. Custos do relacionamento com o parceiro.

15. Como eu avalio alguns custos que a minha empresa tem no relacionamento com o parceiro. Dê uma nota dentro da escala de 0 a 10 . Dez sempre representará o maior custo.

\begin{tabular}{|l|l|l|l|l|l|l|l|l|l|l|l|l|}
\hline $\begin{array}{l}\text { Os acordos logísticos são renegociados } \\
\text { automaticamente e de forma tranquila }\end{array}$ & 0 & 1 & 2 & 3 & 4 & 5 & 6 & 7 & 8 & 9 & 10 & $\begin{array}{l}\text { Há muito tempo despendido nas } \\
\text { renegociações dos acordos }\end{array}$ \\
\hline $\begin{array}{l}\text { Não há investimento em maquinário ou TI } \\
\text { diante de um novo projeto com o parceiro }\end{array}$ & 0 & 1 & 2 & 3 & 4 & 5 & 6 & 7 & 8 & 9 & 10 & $\begin{array}{l}\text { Há alto investimento em maquinário ou } \\
\text { TI diante de um novo projeto }\end{array}$ \\
\hline $\begin{array}{l}\text { Não há treinamento de funcionário diante de } \\
\text { um novo projeto com o parceiro }\end{array}$ & 0 & 1 & 2 & 3 & 4 & 5 & 6 & 7 & 8 & 9 & 10 & $\begin{array}{l}\text { Há muito treinamento diante de um } \\
\text { novo projeto com o parceiro }\end{array}$ \\
\hline $\begin{array}{l}\text { Novos projetos logísticos envolvem pouco } \\
\text { tempo de espera nas negociações }\end{array}$ & 0 & 1 & 2 & 3 & 4 & 5 & 6 & 7 & 8 & 9 & 10 & $\begin{array}{l}\text { Novos projetos logísticos envolvem } \\
\text { muito tempo de espera nas negociações }\end{array}$ \\
\hline $\begin{array}{l}\text { Não há espera para resolução de } \\
\text { contingências logísticas. Elas } \\
\text { são resolvidas imediatamente }\end{array}$ & 0 & 1 & 2 & 3 & 4 & 5 & 6 & 7 & 8 & 9 & 10 & $\begin{array}{l}\text { Há muita espera na resolução de } \\
\text { contingências logísticas. Elas demoram } \\
\text { a serem resolvidas }\end{array}$ \\
\hline
\end{tabular}

